\title{
A Rare Case of Ovarian Tumor
}

\section{Gitajali Kumari ${ }^{1 *}$, Vaishali Taralekar ${ }^{2}$, Suchita Dhabadkar ${ }^{3}$ and Jyoti Rathi ${ }^{1}$}

${ }^{1} 3^{r d}$ Year Post-Graduate Resident, Department of Obstetrics and Gynecology, Bharati Vidyapeeth Deemed University, Pune, India

${ }^{2} H O D$, Professor, Department of Obstetrics and Gynecology, Bharati Vidyapeeth Deemed University, Pune, India

${ }^{3}$ Associate Professor, Department of Obstetrics and Gynecology, Bharati Vidyapeeth Deemed University, Pune, India

*Corresponding author: Gitajali Kumari, $3^{\text {rd }}$ Year Post-Graduate Resident, Department of Obstetrics and Gynecology, Bharati Vidyapeeth Deemed University, Pune, India

\section{Introduction}

Ovarian cancer is the third most common cancer in Indian women, accounting for $3 \%$ of all malignancies and $6 \%$ of deaths from cancer. It is fifth most common cause of death from malignancy in women [1].

Ovarian cancer is associated with low parity and infertility. Because parity is inversely related to the risk of ovarian cancer, having at least one child is protective for the disease, with a risk reduction of 0.3 to 0.4 [2].

This case is presented to highlight the varied presentation of ovarian masses and to outline the approach of management of ovarian mass in perimenopausal patients and to highlight the importance of ruling out gastrointestinal malignancy before proceeding for surgery. Metastatic tumours to the ovaries are most frequently from the breast and gastrointestinal tract. Krukenberg tumours can account for about $2 \%$ of ovarian cancers at some institutions, and they are usually bilateral. The lesions are usually not discovered until the primary disease is advanced, and, therefore, most patients die of their disease within 1 year. In some cases, a primary tumour is never found [3].

Before exploration for an adnexal tumour in a woman older than 40 years, a barium enema is indicated to exclude a primary gastrointestinal carcinoma with metastases to the ovaries, particularly if there are any gastrointestinal symptoms [4].

In first two decades of life almost $70 \%$ of ovarian tumours are of germ cell origin, and one-third of these are malignant [5].

- The peak incidence of invasive epithelial ovarian cancer is at about 60 years of age. About $30 \%$ of ovarian neoplasms in postmenopausal women are malignant, whereas only about $7 \%$ ovarian epithelial tumours in premenopausal women are frankly malignant [6].

- Most epithelial ovarian cancers are sporadic but at least $5-10 \%$ result from inherited susceptibility and are hereditary.

Of all the gynaecologic cancers, ovarian malignancies represent the greatest clinical challenge because they have a high mortality.

A woman's risk at birth of having ovarian cancer at some point in her lifetime is $1 \%$ to $1.5 \%$ and that of dying from ovarian cancer is almost $0.5 \%$ [7].

\section{Case Presentation}

- My patient Mrs X, 43-year-old, nulligravida, got admitted on $9^{\text {th }}$ July in the department gynaecology with complaints of pain in abdomen since 4-5 months.

- Pain was insidious in onset gradually progressive, generalized to whole abdomen, no aggravation or relieving factor, no association with food intake.

- There was no history of palpable lump or any obvious swelling. She also gives history of weight loss and loss of appetite.

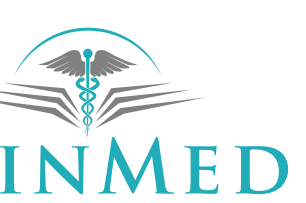

INTERNATIONAL LIBRARY

Citation: Kumari G, Taralekar V, Dhabadkar S, Rathi J (2021) A Rare Case of Ovarian Tumor. Obstet Gynecol Cases Rev 8:198. doi.org/10.23937/2377-9004/1410198

Accepted: April 03, 2021: Published: April 05, 2021

Copyright: (c) 2021 Kumari G, et al. This is an open-access article distributed under the terms of the Creative Commons Attribution License, which permits unrestricted use, distribution, and reproduction in any medium, provided the original author and source are credited. 


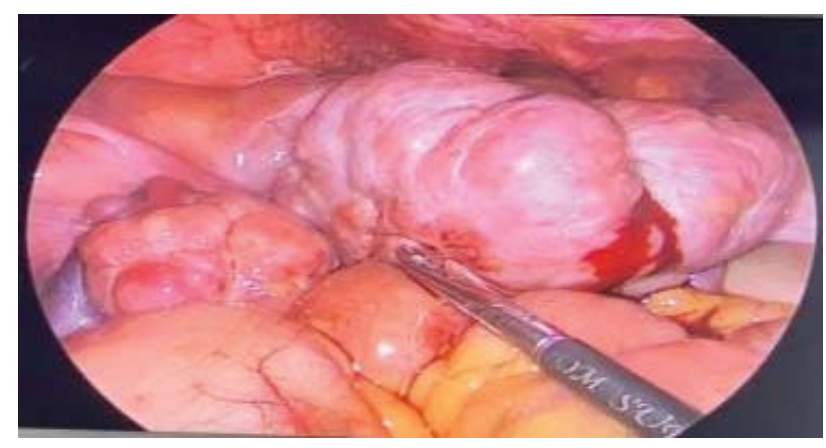

Figure 1: Intraoperative picture of bulky ovary during laparoscopic cholecystectomy.

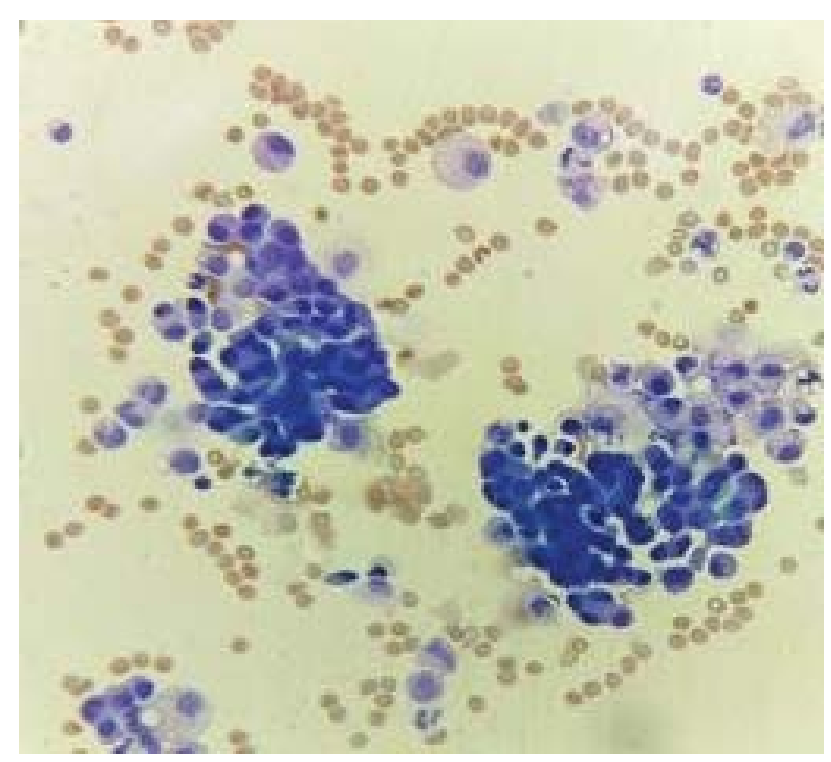

Figure 2: Ascitic fluid with SS highly cellular smears, cells singly scattered, eccentric placed nuclei, pale cytoplasm with vacuoles in many cells, some nuclei are hyperchromatic.

- No c/o heavy menstrual bleeding, no h/o intermenstrual bleeding, no c/o abdominal distension, no bowel or bladder complaints.

- Her Ultrasound report done outside showed gallbladder polyp with bilateral enlarged ovary.

- She was operated for lap cholecystectomy on $27 / 6 / 20$. She was detected to have bulky ovaries intraoperatively (Figure 1) and her ascitic fluid showed cells suspicious of malignancy (Figure 2).

- Her CA-125 was 66.

- Hence her staging laparotomy with frozen section with pan hysterectomy was planned.

\section{Menstrual history}

- Last menstrual period- $6 / 6 / 2020$

- Past Menstrual history- 4-5 days/28-30 days/Regular

- No history of heavy menstrual bleeding, No history of passage of clots

\section{Obstetric history}

Married since 23 years, Nulligravida

\section{General examination}

- Patient was conscious, Oriented,

- No pallor/icterus/edema/lymphadenopathy

- PR- 80 bpm, BP 110/70 mmHg

\section{Systemic check-up}

R.S - clear, Bilateral air entry equal

CVS - NAD

Breast - Normal

$P / A-$

Inspection -

- Abdomen uniformly distended umbilicus inverted, No dilated veins, Visible peristalsis, Laparoscopy scar + healthy

Palpation - Soft nontender, No mass palpable, No evidence of free fluid

\section{Percussion - Resonant}

Auscultation - Bowel sounds present

Per speculum - Cervix, Vagina - Looks normal

Minimal white discharge present

$\mathrm{P} / \mathrm{v}$ - uterus - Bulky, Anterior fornix fullness +/Posterior fornix free

Right lateral fornix fullness present, No finical tenderness

$\mathbf{P} / \mathbf{R}$ - No growth felt mucosa intact parametrium free

Based on my clinical findings my diagnosis is 68-yearold postmenopausal women with some adnexal pathology probably malignancy.

\section{Investigation}

$\mathrm{Hb} / \mathrm{Tlc} /$ Platelet - 12.2/10,000/3.35

Serum beta HCG $-<1.20$

CA - 125- 66

LDH - 1104

Cytology report - Ascitic fluid - Suspicious for malignancy

PAP smear - NILM

\section{CTSCAN (Abdomen + Pelvis)-24/5/2020}

UTERUS - Appear normal, right ovary enlarged $7.6 \times$ $6.4 \mathrm{~cm}$ shows cystic lesion measuring $4 \times 2.8 \mathrm{~cm}$ within. Left ovary enlarged $5.2 \times 4.4 \mathrm{~cm}$ in size. No abdominal/ pelvic lymphadenopathy.

\section{USG Abdomen \& Pelvis ON 24/6/2020}

Uterine outlines are poorly visualised due to the pel- 
vic mass. Endometrium measures $6 \mathrm{~mm}$. Right ovary measures $8.2 \times 6.8 \times 4.5 \mathrm{~cm}$., Left ovary measures 5.2 $\times 5.1 \times 4.4 \mathrm{~cm}$.

Both ovaries are enlarged, Hypoechoic \& Heterogonous in echotexture. They show raised vascularity. Small amount of free fluid is seen in pod and interbowel Region. No significant para-aortic lymphadenopathy.

Procedure: Exploratory Laprotomy + TAH + BSO + Omenectomy + Appendicetomy

Anaesthesia: General + Epidural

\section{Intraoperative findings-}

- Incision: Midline vertical

- Minimal ascites noted - Fluid collected for histopathology

- Omental thickening present

- Appendix thickened

- Liver and under surface of diaphragm were normal

- Evidence of b/l ovarian masses around $8 \times 9 \mathrm{~cm}$ with irregular surfaces

- Pouch of Douglas thickening present on both

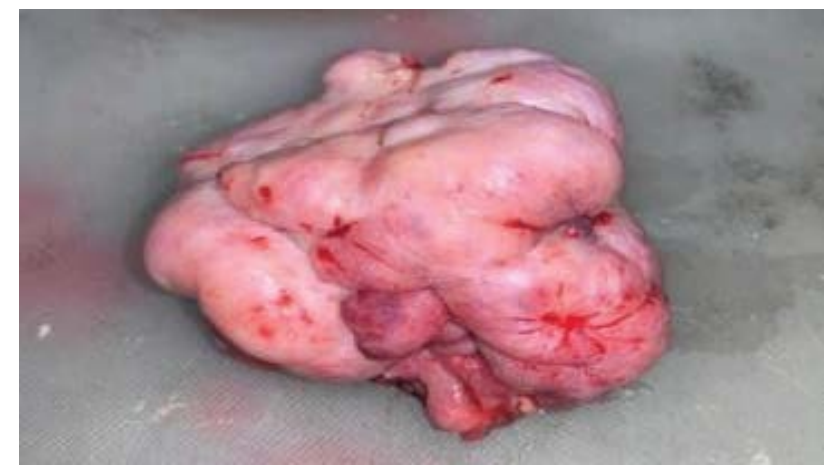

Figure 3: Right ovary of $8 \times 8 \times 5 \mathrm{~cm}$, with nodular external surface and intact capsule.

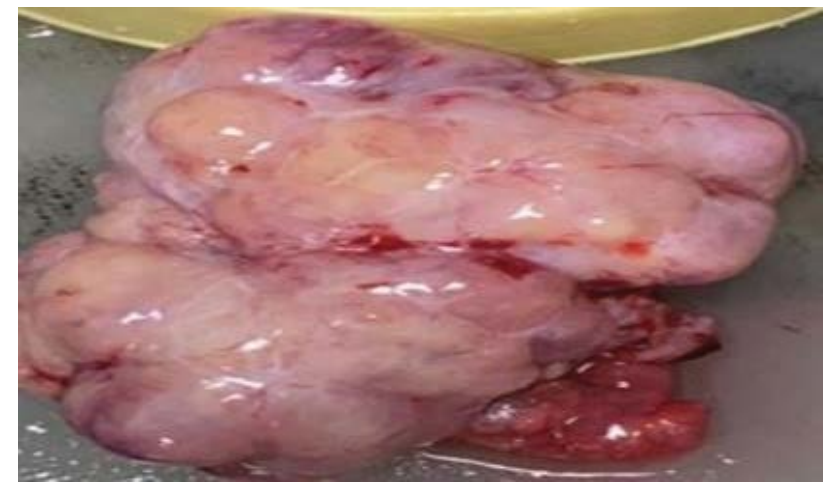

Figure 4: Specimen of left ovary, $7 \times 7 \times 3.5 \mathrm{~cm}$. External surface nodular, capsule intact. Ovarian mass on cut section shows yellowish to whitish homogenous area, Fallopian tube intact $(5 \mathrm{~cm})$. uterosacral. Right parametrium thickening present

- Bilateral Ovarian masses removed and sent for Frozen section

- Appendectomy done, partial infracolic omentectomy done

- Frozen section - Suggestive of granulosa cell tumour (Figure 3, Figure 4 and Figure 5)

- Specimen was sent for histopathology

\section{Final Histopathological Diagnosis}

\section{Final diagnosis-> Poorly differentiated malignancy of both ovaries}

- Lymphovascular emboli seen

- Right fallopian tube is involved while left FT is free

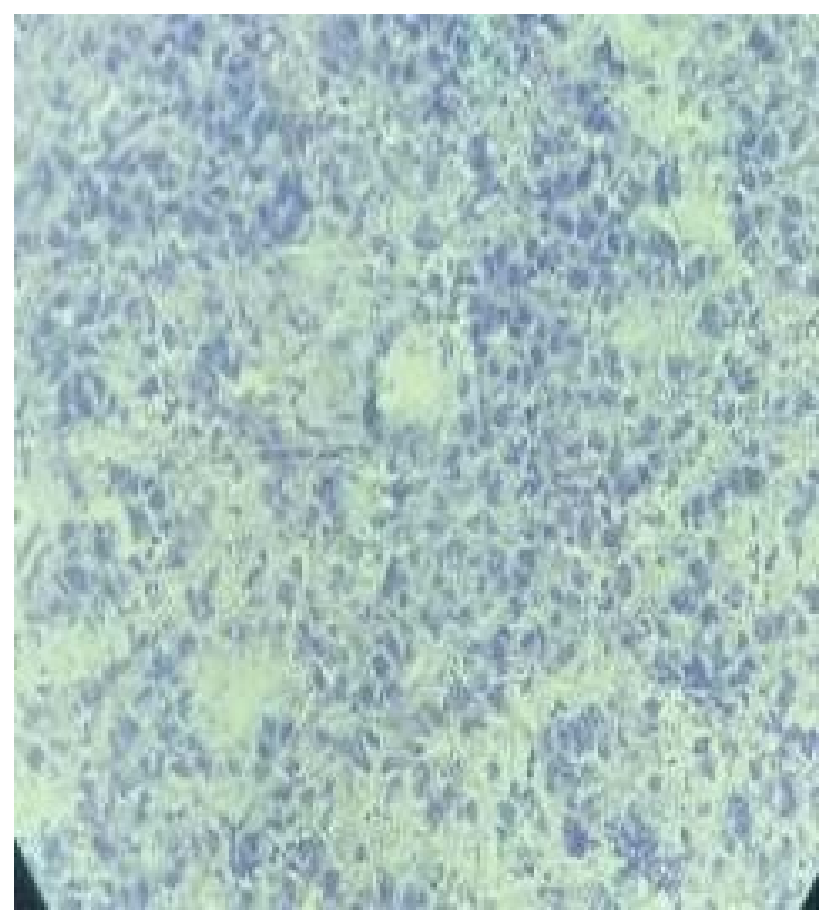

Figure 5: Tumor cells arranged in solid sheets and microfollicular pattern -> Call exner bodies.

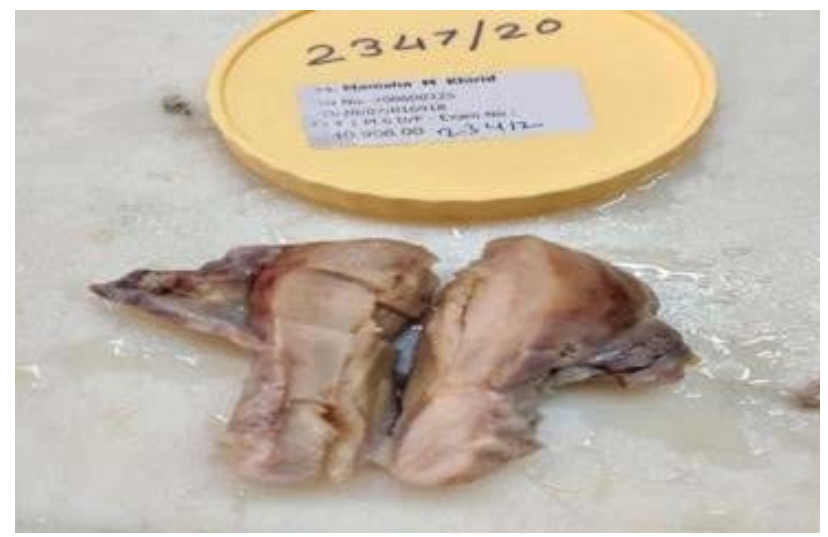

Figure 6: Uterus and cervix. 


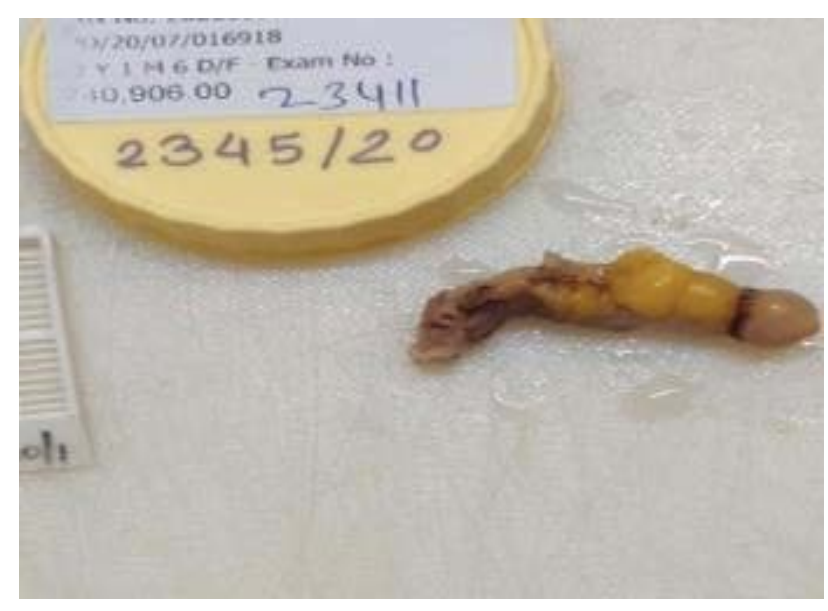

Figure 7: Appendix specimen.

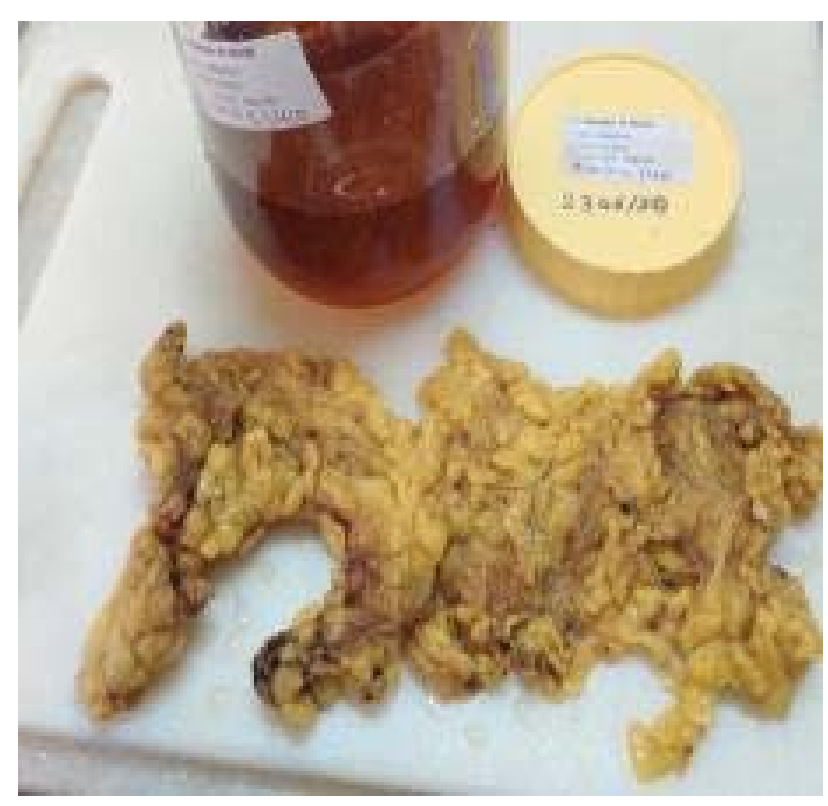

Figure 8: Omentum specimen.

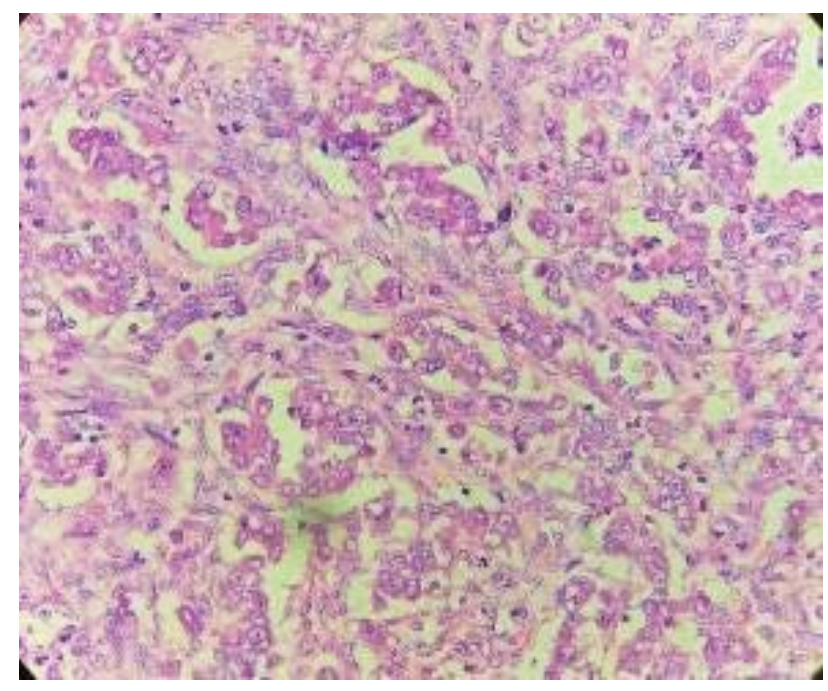

Figure 9: Microscopic -2 types of Tumour cells, Glandular pattern, Others are spindle shaped with elongated nuclei, prominent nucleoli with increased $\mathrm{N}: \mathrm{C}$ ratio and scant to moderate amount of eosinophilic cytoplasm.
- Cervix, endomyometrium are free (Figure 6)

- Bilateral parametria are free

- Omentum and the wall of appendix show tumour deposits (Figure 7, Figure 8 and Figure 9)

D/D:1. Suggestive of metastatic adenocarcinoma

2. Malignant sex cord stromal tumour

IHC advised: CK7, CK20, Inhibin

\section{Post-operative}

Patients' histopathology report came as metastatic adenocarcinoma or Malignant sex cord tumour. Her IHC marker of IHC- CK7 AND CK 20 POSITIVE, INHIBIN - NEGATIVE Which was favouring adenocarcinoma.

- Post-operative patient underwent 2 cycles of chemotherapy.

- She presented with acute abdomen after 1 month of surgery and was diagnosed with bowel perforation -> ileostomy was done.

- Colostomy bag was put. Patient was shifted to ICU postoperatively for further management.

- She was shifted towards on $\left(0+3^{\text {rd }}\right)$ post-operative day and was discharged on $10^{\text {th }}$ postoperative day.

- She didn't follow up later.

\section{Discussion}

Early ovarian cancer has nonspecific symptoms resembling those of less serious conditions. Pain in abdomen and burning micturition are common complaints which may present to a general-practioner. Thus, the diagnosis of ovarian cancer is challenging, since it is detected at an advanced stage, requiring exploratory laparotomy.

Whenever a patient of ovarian tumour is posted for surgery the staging laparotomy with frozen section remains the preferred approach.

\section{Conclusion}

In this case the patient presented with vague symptoms. Ovarian cancers present with very vague symptoms; hence it is generally diagnosed in very late stage, hence whenever any perimenopausal women presents to a Primary health care with vague symptoms, possibility of ovarian cancer must be kept in mind and per vaginal examination to rule out any adnexal pathology must be done and they must be referred to tertiary care hospital for further management. Also, Gastrointestinal malignancy or Krukenberg tumour must be kept in mind as differential diagnosis of carcinoma ovary and CEA also should be done.

Frozen section may not be conclusive in every case of ovarian tumor, so staging laparotomy is ideal modality of management. 


\section{References}

1. (2006) Consolidated report of population based cancer registries 2001-2004. National cancer registry program. Indian Council of Medical Research, Bangalore, India.

2. Bell DA, Scully RE (1991) Clinical perspectives on borderline tumors of the ovary. In: Greer BE, Berek JS, Gynecologic oncology: Treatment rationale and techniques. Elsevier Science, New York, 1991: 119-134.

3. Berek JS, Friedlander M, Hacker NF (2009) Epithelial ovarian, fallopian tube and peritoneal cancer. In: Berek, Hacker S, Gynecologic oncology. ( $5^{\text {th }}$ edn), Lippincott Williams \& Wilkins, Philadelphia, 443-508.

4. Callahan MJ, Crum CP, Medeiros F, Kindelberger DW, Elvin JA, et al. (2007) Primary fallopian tube malignancies in
BRCA-positive women undergoing surgery for ovarian cancer risk reduction. J Clin Oncol 25: 3985-3990.

5. Crum $C P$, Drapkin $R$, Miron $A$, Ince $T A$, Muto $M$, et al. (2007) The distal fallopian tube: A new model for pelvic serous carcinogenesis [review]. Curr Opin Obstet Gynecol 19: 3-9.

6. Seidman JD, Kurman RJ (1996) Subclassification of serous borderline tumors of the ovary into benign and malignant types: A clinicopathologic study of 65 advanced stage cases. Am J Surg Pathol 20: 1331-1345.

7. Michael H, Roth LM (1986) Invasive and noninvasive implants in ovarian serous tumors of low malignant potential. Cancer 57: 1240-1247. 